\title{
The International Cooperation on Remote Laboratories in the Framework of Engineering Didactics
}

\author{
http://dx.doi.org/10.3991/ijep.v5i1.3917 \\ Raivo Sell and Tiia Rüütmann \\ Tallinn University of Technology, Tallinn, Estonia
}

\begin{abstract}
In the present paper the interactive demonstration of remote laboratories conducted with engineering didactics for creating real conditions for teaching and learning engineering has been presented. The article is focusing on international cooperation, offering the wide range of tools and methodology for effective and interactive teaching of embedded systems and mechatronics as well as exploiting latest web technologies, and offering flexibility and freedom for students.
\end{abstract}

Index terms - remote lab; robotics; embedded system; elearning.

\section{INTRODUCTION}

The dominant teaching model in engineering is deductive, where a teacher takes full control of the transmission of knowledge - this model regards a teacher as an expert and students as a group of novices. The process of learning, thinking, and doing sends a powerful message that students receive as information about how engineers work. Numerous textbook problems, students have to solve, do not sufficiently challenge them to move to a deeper level understanding and skill of analysis that helps towards critical thinking. Learning to use concepts to analyze real-world problems is an important goal in teaching engineering, but students have very little opportunity to develop these skills today.

Inductive teaching is one way to help students learn to use the fundamental concepts for problem solving - focusing on cases that students could work on to help develop an understanding of the phenomenon before a principle is introduced. To be effective in this method hands-on experience is essential. However, today's teaching and learning process needs much more flexibility and use of different mediums. Classical lecture-exercise-exam method cannot fulfill anymore today's needs. Information and new knowledge is quite often acquired by students from Internet. This is their normal environment and to be successful of teaching engineering we need to offer also engineering subjects over the Internet, but not only as uploaded material, but interactive and real hands-on practical tasks. This is not trivial task and needs most advanced technology as well as new teaching concept in highest level. For engineering studies, online and remote labs are starting to develop in recent years. Even most of them are in experimental stage, more and more real systems can be found and used in real study process and not only for piloting. In the present article the concept of inductive principles in Engineering Pedagogy on the example of remote labs will be presented. The first part introduces concept of new engineering pedagogy and presents most recent trends and advancements. Second part of the paper presents an overview of remote lab system developed in the frame of Lifelong Learning projects and is currently in active use by several vocational schools and universities. The system supports the inductive teaching.

\section{ENGINEERING DIDACTICS}

Students learn with understanding when they develop a conceptual framework for the facts, transferring and applying what they have learned to new situations, thus developing professional competence and learning by doing.

It is critical in engineering didactics to distinguish between different paths, analyze, evaluate, and create, providing [7]:

- Ability to apply knowledge of STEM (science, technology, engineering and mathematics).

- Ability to design and conduct experiments, as well as to analyze and interpret data.

- Ability to design a system, component, or process to meet desired needs.

- Ability to function on multi-disciplinary teams.

- Ability to identify, formulate and solve engineering problems.

- Understanding of professional and ethical responsibility.

- Ability to communicate effectively.

- Broad education necessary to understand the impact of engineering solutions in a global and societal context.

- Recognition of the need for, and an ability to engage in life-long learning.

- Knowledge of contemporary issues.

- Ability to use the techniques, skills, and modern engineering tools including online tools necessary for engineering practice.

Remote labs create real conditions for students' learning on mentioned abilities and reaching required knowledge.

New teaching methods may be integrated in teaching, while using remote labs. Flipped teaching is a form of blended learning in which students learn new content online by watching video lectures and simulations in ad- 
vance usually at home. Flipped classrooms free class time for hands-on work, where students learn by doing, asking, actively participating in group work.

Current technology allows students to be immersed into impossible spaces or environments thanks to virtual reality techniques. Remote labs help students to understand better the real behavior of the concepts they learn in class, thus comparing theoretical calculations they learn with the real world processes.

By using the principles and strategies of team-based learning it is possible to develop and take advantage of higher performance and deep understanding in an educational situation presented by remote labs. Students are more interested to commit to a higher level of effort in learning and helping each other. Learning teams from the other side are more capable of solving very challenging and complex problems.

\section{INTERNATIONAL COOPERATION}

\section{A. Cooperation within International Society for Engineering Education (IGIP)}

Estonian Center for Engineering Pedagogy has developed international cooperation within International Society for Engineering Education (IGIP) [8] in the field of engineering didactics. In the field of robotics the international cooperation has been developed by the support of Life Long Learning projects, starting with Pilot project and followed by Transfer of Innovation projects. The recent activities are transfers from Estonia to Lithuania and Portugal. In most cases the transfer of innovation is bi-directional, meaning that some knowledge will be also transferred to source country and organizations.

International cooperation of Estonian Centre for Engineering Pedagogy in the field of robotics, robotic didactics and remote laboratories has been carried out within IGIP working groups:

- Knowledge Management and Computer-aided Technologies.

- International Aspects of Engineering Education.

- Pre-University Engineering Education (K-12).

- Research in Engineering Pedagogy and Engineering Education.

- Technical Teacher Training.

- Working with Projects.

\section{B. Unified Solution of Remote Access in Practical}

Vocational Engineering Education - USORA

Recently, in October 2013, new activity - USORA [2] was initiated. The consortium is formed from different institutions from Portugal, Estonia, and Germany (see Fig. 1) which aims to bring the international cooperation on the remote labs into new level.

The main idea of the project is to unifying the idea of accessible remote labs - DistanceLab and VirtualLab. USORA creates a way to increase educational quality, opportunities, creativity and competitiveness in lifelong learning for all. Partners integrate different relevant members in education and training seeking cooperation and quality for the USORA process of transferring innovation. The USORA framework provides support for participants in the use of knowledge in different contexts, improving

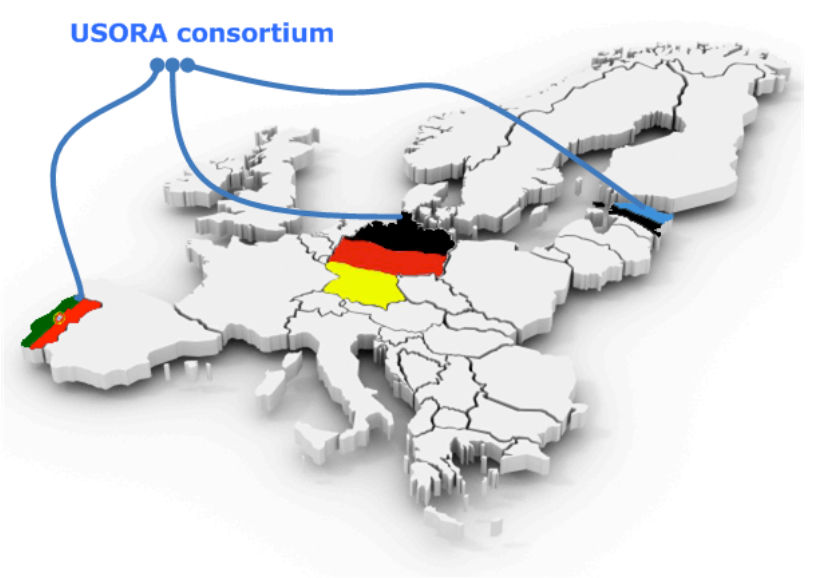

Figure 1. USORA consortium

the attractiveness of continuous education and mobility during the educational process and creating an innovative and attractive learning system that helps to tackle the issue of premature school leaving.

The framework approach is highly practical and enables learners to:

- Acquire new skills and competences through experimentation.

- Access hands-on learning through educational content and exercises.

- Improve recognition of qualifications and competences (through targeting of creativity and innovation).

Relevant information and practices for the different European educational qualifications frameworks can be obtained in USORA. The project is also about the cooperation between the worlds of education and training. Educational content and laboratory exercises are open, specific problems or demands for lab use from the different educational institutions or the labor market can easily emerge and be included in the framework. USORA promotes the development, transfer and evolution of reusable units of learning aims for educational quality and excellence, empowering the use of these units in different VET professionals with organizational, technical and qualityrelated issues linked to ECVET.

The work of the consortium focuses on the prioritized fields of all countries and is developing the solution for the gaps of vocational education in engineering in general but more precisely in mechatronics, ICT and embedded system domain. Those domains are defined as national priorities in Estonia (Research and development plan and innovation strategy in Estonia 2013, Parliament resolution) and expected results are directly focused on the prioritized actions, defined in "Development Plan of Vocational Education System in Estonia". Most of the partner countries, as well as the EU parliament, have defined similar priorities in different documents, strategies and development plans which are directly related to the expected results of this project.

Mobility and accessibility are core issues in USORA Distance and Virtual Labs. Like many other remote learning and eLearning examples, it targets integration and development dynamics for new educational content. USORA develops and disseminates reusable units of 
learning aimed at educational quality and excellence, empowering the use of these units by different VET professionals, with organizational, technical and qualityrelated issues linked to ECVET.

USORA is a framework instrument with procedures and methods for improving the quality of VET systems. The USORA framework is implementing lifelong learning strategies to enable more flexible learning pathways, improving the quality and efficiency of education and training with its centralized laboratory solutions. Development and transfer of innovative practices in the field of education and training between the different European labs equipped with USORA is creating a network of laboratories that can support and complement each other and integrate new setups, experiments and exercises.

A web-based remote laboratory facility will not replace the real hands-on experience of engineering students. It can, however, be used to supplement laboratory hours and allow more time for students to familiarize themselves with past or future experiments, as well as to learn the background to these experiments through the addition of supplementary learning material for each experiment. There are considerable "logistical" benefits of remote and virtual laboratories: flexibility, cost, and resource sharing. Attention needs to be given to the impact that a change to remote laboratories has on student learning outcomes. Having the same framework working simultaneously in different locations will increase knowledge transfer, develop expertise and improve collaboration for the implementation of new learning methodologies.

\section{Labs in Portugal}

On the frame of USORA project several new remote labs compatible with Robotic Teaching and Learning Concept (RTLC) are on the development stage. These labs will be connected to the Remote Lab Center (RLC) eenvironment and can be accessed by users around the world. At first stage, three institutions from Portugal are involved with the project:

- Artica CC - as a coordinator and developer.

- Association of Instituto Superior Técnico for Research and Development (IST-ID) - as technology tester and advisor.

- Estudos Técnicos e Profissionais (INETE) - as piloting organization.

The main technology of remote lab is transferred from Estonia, developed by ITT Group (Robolabor.ee) and Tallinn University of Technology. The concept includes also virtual lab - AVR microcontroller simulation environment which is developed by German partners: it:matters and Bochum University of Applied Sciences.

New labs will be involved into the DistanceLab [9] environment. Initial device in these new labs will be Robotic HomeLab kit test bench [10] in Artica CC and IST-ID. Second main development is to include well known Arduino [11] microcontroller platform into the DistanceLab environment. Remote microcontroller test bench set up is shortly described in chapter $\mathrm{V}$.

\section{STRUCTURE OF THE E-ENVIRONMENT}

The e-environment which is the base of remote lab centers is a part of a Robotic Teaching and Learning Concept presented in the paper [12]. The concept offers wide range

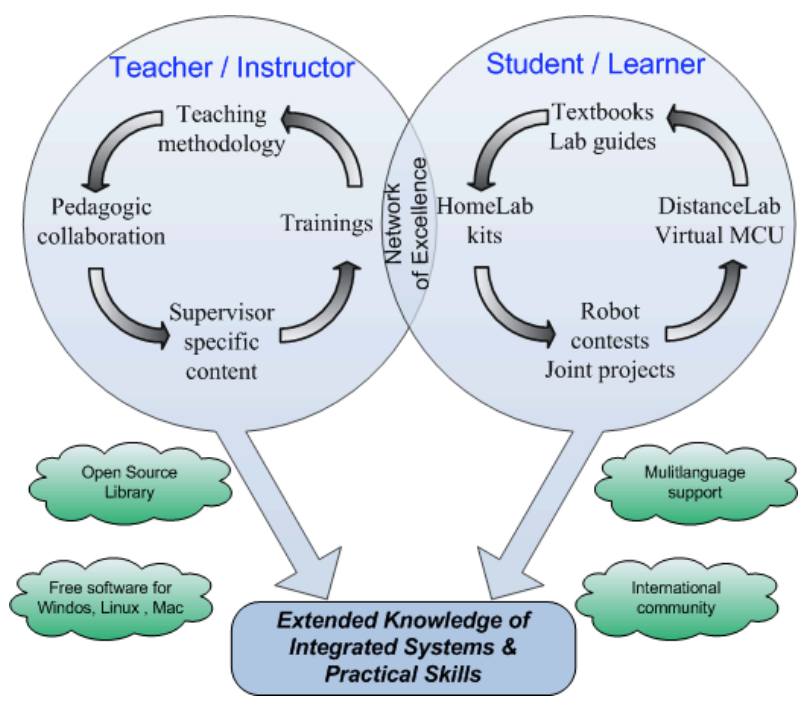

Figure 2. Robotic Teaching and Learning concept

of tools and methodology to effectively and interactively teach embedded systems and mechatronics as well as exploit latest web technologies. Figure 2 describes the concept components and shows didactic focuses and practical tools.

As seen on the Fig. 2 the Virtual MCU (Micro Controller Unit) is a part of didactic tool combined with DistanceLab environment. DistanceLab environment consist of several Remote Lab Centers (RLC) which are specific location-based labs accessible over the Internet. A Remote Lab Center focuses on specific equipment or a series of experiments by giving online access, enabling control and monitoring of the process. Remote Lab Centers are located in different organizations like universities, vocational schools, SME-s and offer through a resource sharing concept, different remote labs, such as; mobile robot lab, microcontroller test bench, automotive lab and smart house lab.

\section{DEMONSTRATION OF LABS}

Demonstration of the labs is based on the most used RLC - Robotic HomeLab kit test bench (Fig. 3) located in Robolabor.ee in Estonia. The lab is assembled from the hardware found in the Robotic HomeLab kit [9] and can be programmed over the Internet. Example codes are presented to study basic functionality on embedded systems as following:

- Digital outputs.

- Analog inputs (temperature, light intensity, distance sensing).

- Displays and indicators.

- Motors and digital actuators; etc.

Similar test bench based on Arduino micro controller [10] is under the development and will be integrated into DistanceLab web portal during the February 2014. The physical setup is seen in Fig. 4.

In similar to Robotic HomeLab kit test bench, the Arduino test bench has following features:

- Analog inputs (temperature, light intensity).

- Display (alphanumeric LCD).

- Motors (DC motors - low and high speed and servo motor). 


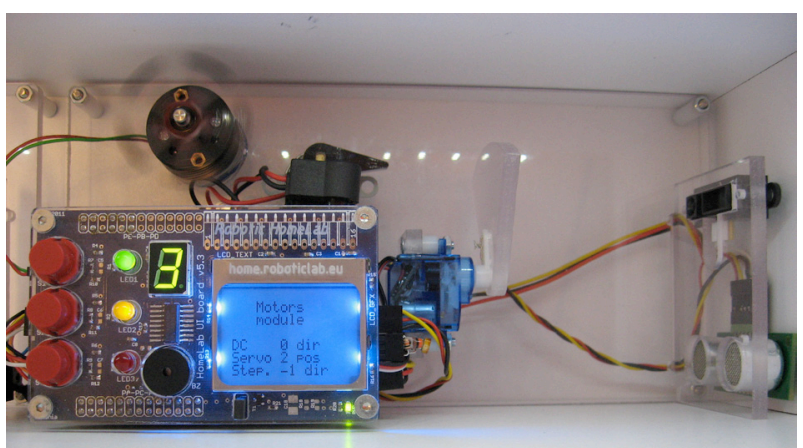

Figure 3. Robotic HomeLab kit test bench in Robolabor.ee

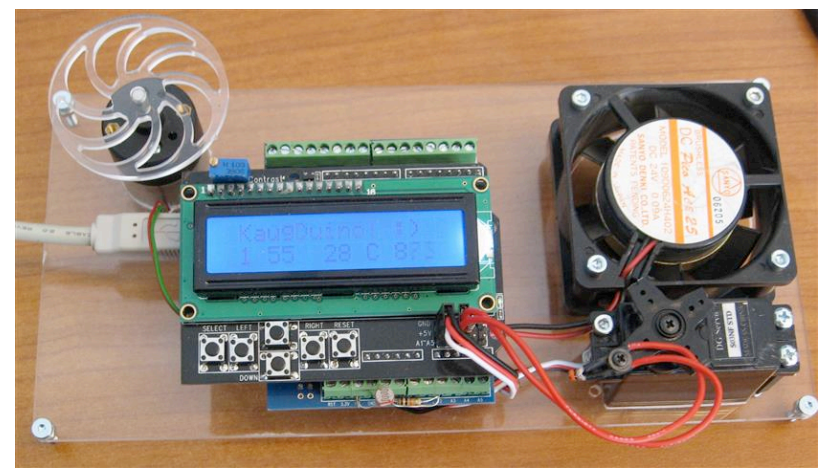

Figure 4. Arduino kit test bench in Robolabor.ee

The main difference between Robotic HomeLab kit and Arduino test bench is the programming language and interface. Arduino has simplified programming language based on Wiring [13] which is an open-source programming framework for microcontrollers. Robotic HomeLab kit, however uses standard $\mathrm{C}$ programming language which is most common in nowadays microcontroller programming. Nevertheless the Wring language combined with Arduino platform is easier for beginners and therefore suggested as a starting point of microcontroller studies. When student has been familiarized with microcontroller concepts with Arduino he/she can go to next step and start experimentations with Robotic HomeLab kit and $\mathrm{C}$ language which is more advanced and industry oriented approach.

\section{CONCLUSIONS}

The remote lab e-environment DistanceLab found on website: http://distance.roboticlab.eu offers real-time access to different remote labs all over the Europe and pursuits the international collaboration between didactic centers, universities and SME-s as well as between students from different countries. The recent activities between Estonia and Portugal are demonstrated in more detail, where the main purpose is to archive the extended knowledge of integrated systems and practical skills of students. On the frame of described project (USORA) a mutual transfer of innovation is the aim to enrich and integrate the innovative web and robotic developments in both countries: Estonia and Portugal as well as third partner - Germany. New labs are under the development to be included into DistanceLab environment in near future which enables to start multinational robotic projects among the students by using different and complementary remote labs.

\section{ACKNOWLEDGEMENT}

The development of described concept is supported by EU Life Long Learning program project NetLab from Estonia, USORA from Portugal and ViReal from Lithuania. In addition the scientific development of remote access and resource sharing framework is supported by Estonian Research Council grant ETF8652.

\section{REFERENCES}

[1] Learning Situations for Embedded System Study Lab - NetLab, 2011-0019-LEO05-TOI-01, Life Long Learning project, 2011.

[2] Unified Solution of Remote Access in Practical Vocational Engineering Education - USORA, 2013-1-PT1-LEO05-15527, Life Long Learning project, 2013.

[3] Virtual \& Distance Labs environment for Industrial Engineering education - ViReal, LLP-LdV-TOI-2012-LT-0104, Life Long Learning project, 2013.

[4] S. Seiler, R. Sell, D. Ptasik and M. Bölter, Holistic web-based Virtual Micro Controller Framework for research and education, in International Journal of Online Engineering, vol 8, nr 4, pp. 5864, 2012.

[5] R. Sell, S. Seiler, Improvements of Multi-disciplinary Engineering Study by Exploiting Design-centric Approach, Supported by Remote and Virtual Labs, in International Journal of Engineering Education, vol. 28, issue 4, pp. 759-766, 2012.

[6] S. Seiler, R. Sell and D. Ptasik, Embedded System and Robotic Education in a Blended Learning Environment Utilizing Remote and Virtual Labs in the Cloud, Accompanied by 'Robotic HomeLab Kit', International Journal of Emerging Technologies in Learning, Vol 7, Issue: 4, pp. 26-33, 2012.

[7] Crawley E., Malmqvist J., Östlund S., Brodeur D., Rethinking Engineering Education. The CDIO Approach., Springer, 2009.

[8] IGIP - International Society for Engineering Education, www.igip.org (retrieved on October 29, 2013).

[9] DistanceLab portal http://distance.roboticlab.eu, (retrieved on January 10, 2014).

[10] Robotic HomeLab kit - Network of Excellence, http://home.roboticlab.eu, (retrieved on January 10, 2014).

[11] Arduino - Open source microcontroller platform, http://arduino.cc, (retrieved on January 10, 2014).

[12] R. Sell, T. Rüütmann and S. Seiler, Inductive Principles in Engineering Pedagogy on the Example of Remote Labs, The 2nd Experiment@ International Conference, Coimbra, Portugal, 2013.

[13] Wiring programming language, http://wiring.org.co/, (retrieved on January 10, 2014).

\section{Authors}

Raivo Sell and Tiia Rüütmann are with Tallinn University of Technology, Tallinn, Estonia.

Submitted 29 May 2014. Published as resubmitted by the authors 14 February 2015. 